\title{
DA CONCEPČ̃̃O AO EMPREGO: O PROGRAMA ESTRATÉGICO DO EXÉRCITO GUARANI
}

Um programa sob medida para a conjuntura regional

Ten Cel Kenji Alexandre Nakamura ${ }^{1}$

\section{RESUMO}

Este artigo apresenta a contextualização do Programa Estratégico do Exército GUARANI no Processo de Transformação do Exército Brasileiro que ora está em curso, evidenciando a sua contribuição para a manutenção da capacidade dissuasória da expressão militar do Poder Nacional, ao mesmo tempo que traz grandes benefícios para o desenvolvimento da Base Industrial de Defesa e para o bem-estar e segurança da sociedade.

Palavras-chave: Programa Estratégico do Exército GUARANI, Transformação, Capacidades, Base Industrial de Defesa, Plano Estratégico do Exército, Portfólio Estratégico do Exército, Dissuasão

\section{RESUMEN}

Este artículo presenta la contextualización del Programa Estratégico del Ejército GUARANI en el Proceso de Transformación del Ejército Brasileño que ahora está en marcha, evidenciando su contribución al mantenimiento de la capacidad disuasiva de la expresión militar del Poder Nacional, al mismo tiempo trae grandes beneficios para el desarrollo de la Industria de la Defensa y para el bienestar y seguridad de la sociedad.

Palabras clave: Programa Estratégico del Ejército GUARANI, Transformación, Capacidades, Base Industrial de Defensa, Plan Estratégico del Ejército, Portfolio Estratégico del Ejército, Disuasión

\footnotetext{
1 knakamurabr@gmail.com
} EJÉRCITO DEL BRASIL 


\section{Introdução}

A partir de meados da década de 1990, o Exército Brasileiro (EB) passou a conduzir o seu preparo sob o contexto da chamada "Doutrina Delta", cuja concepção geral tinha como referencial as operações militares executadas durante a Guerra do Golfo nos anos 1990-1991. Nessa concepção doutrinária, destacava-se a necessidade de se conduzir operações simultâneas e sincronizadas, por meio do combate continuado e em profundidade. Objetivo, ofensiva, manobra, massa e surpresa eram os princípios de guerra mais valorizados naquele momento. Além disso, pontuou-se a importância da conquista de objetivos estratégicos relacionados ao centro de gravidade da força inimiga, bem como a obtenção da superioridade no uso do espectro eletromagnético. Diante desses aspectos, concluiu-se que os elementos mais adequados da Força Terrestre para o emprego nesse cenário operativo eram as forças blindadas e mecanizadas ${ }^{3}$.

A partir de então, o EB passou a conduzir estudos mais aprofundados sobre a adequação e a substituição dos seus meios mecanizados ${ }^{4}$, compostos em sua totalidade pelas viaturas blindadas de reconhecimento EE-9 CASCAVEL e de transporte de tropa EE-11 URUTU, ambas fabricadas pela empresa nacional ENGESA. Essas duas viaturas constituíam o cerne das Brigadas de Cavalaria Mecanizadas do EB. Em que pese a sua bem-sucedida trajetória de emprego operacional até aquele momento, tanto no Brasil como no exterior, esses blindados, que foram incorporados na Força Terrestre na década de 1970, já haviam praticamente chegado ao fim do seu ciclo de vida ${ }^{5}$ operacional, por uma combinação de motivos doutrinários, logísticos e, principalmente, técnicos. Evidentemente, esse panorama não leva em consideração ações pontuais conduzidas em Organizações Militares (OM) logísticas visando o prolongamento da vida útil de determinados lotes dessas viaturas. Verificava-se que as características do ambiente operacional já demandavam Capacidades Operativas (CO) da Força Terrestre que os meios mecanizados em uso já não tinham condições de atender de modo pleno, mesmo que repotencializados.
Já nos anos 2000, prognósticos apontavam para um mundo com mais conflitos irregulares e de baixa intensidade, na qual ameaças ligadas ao crime organizado e ao terrorismo ganhariam mais relevância. Surgia também a tendência do crescente papel da rede mundial de computadores na vida das pessoas, gerando uma revolução na maneira como a sociedade interage e lida com a informação, marcando assim, o início do que se convencionou chamar de "Era do Conhecimento", na qual a Indústria $4.0^{6}$ vem ganhando protagonismo. Com o término da crise financeira mundial de 2007 2008, mudanças intensas passaram a ser verificadas na geopolítica internacional em direção à multipolaridade. Acompanhando todas essas mudanças, os gastos de muitos países em Defesa passaram a crescer consistentemente $^{7}$, particularmente em países não membros da Organização do Tratado do Atlântico Norte (OTAN).

Mais recentemente, na esteira do aumento de gastos militares, conceitos como o de "Conflito em Larga Escala" vem aparecendo com mais frequência em publicações doutrinárias internacionais, contrariando a tendência apresentada por alguns estudos prospectivos passados e evidenciando a volatilidade do mundo atual, bem como a rapidez com que as políticas de Defesa necessitam se ajustar à realidade em voga. Essas considerações impõem às estruturas militares, como também aos Sistemas e Materiais de Emprego Militar (SMEM) modernos a incorporação de conceitos como flexibilidade, adaptabilidade e principalmente modularidade, visando assim não se tornarem obsoletos antes mesmo de saírem das linhas de produção.

Assim sendo, a evolução da conjuntura é captada e analisada pelo Ministério da Defesa (MD) do Brasil, que elabora a chamada Política Nacional de Defesa (PND), documento "de mais alto nível do planejamento de ações destinadas à defesa nacional" e que "estabelece objetivos e orientações para o preparo e o emprego dos setores militar e civil em todas as esferas do Poder Nacional" (Ministério da Defesa, 2012, p. 1), cujo core é a apresentação dos Objetivos Nacionais de Defesa. Desses objetivos, dois estão diretamente relacionados ao desenvolvimento e à obtenção de SMEM

2 Concepção de emprego da Força Terrestre brasileira que antecedeu a atual, constante nas Instruções Provisórias IP 100-1 - Bases para a Modernização da Doutrina de Emprego da Força Terrestre, de 1996. Essas instruções foram revogadas por ocasião da aprovação em 2014 do Manual de Fundamentos EB20-MF-10.102 - Doutrina Militar Terrestre.

3 Conforme o Glossário das Forças Armadas (MD35-G-01), mecanizado é o "termo genérico utilizado para designar toda viatura de combate ou de apoio ao combate, caracterizada pela blindagem leve e deslocamento sobre rodas" (Ministério da Defesa, 2015, p. 165).

4 Em 1997, ocorreu o $1^{\circ}$ Seminário de Doutrina e Emprego da Cavalaria, em que verificou-se a necessidade de iniciar o desenvolvimento de uma nova família de blindados sobre rodas (EME, 2018).

5 Sinteticamente, o ciclo de vida de um material de emprego militar vai "desde a identificação de uma lacuna de capacidade [...]; seu atendimento por intermédio de um [...] material; a confrontação deste com [...] requisitos estabelecidos; a avaliação técnica e operacional; a oportuna revitalização, repotencialização ou modernização até sua desativação" (Comandante do Exército, 2016).

6 Relacionada à quarta revolução industrial, que se caracteriza por um conjunto de tecnologias que permitem a fusão do mundo físico, digital e biológico (MICS - ABDI, 2020).

7 Conforme dados do Stockholm International Peace Research Institute (SIPRI), os gastos militares mundiais foram de 1,8 trilhão de dólares em 2018, representando um aumento de 2,6\% em relação à 2017 (SIPRI, 2019). 
e de CO: "desenvolver a indústria nacional de defesa, orientada para a obtenção de autonomia em tecnologias indispensáveis" e "estruturar as Forças Armadas em torno de capacidades, dotando-as de pessoal e material compatíveis com os planejamentos estratégicos e operacionais" (Ministério da Defesa, 2012, p. 8). Por sua vez, a Estratégia Nacional de Defesa (END) de 2012, documento alinhado com a PND e com os planejamentos estratégicos de longo prazo do Ministério da Economia $^{8}$, chama a atenção para a necessidade da transformação das Forças Armadas brasileiras:

Disposição para mudar é o que a Nação está a exigir agora de si mesma, de sua liderança, de seus marinheiros, soldados e aviadores. Não se trata apenas de financiar e de equipar as Forças Armadas. Trata-se de transformá-las, para melhor defenderem o Brasil (Ministério da Defesa, 2012, p. 2).

Do exposto, a Era do Conhecimento marca um processo histórico de concretização de avanços científicos e tecnológicos em diversas áreas do conhecimento, cujo impacto é decisivo para o bem-estar da população, para as relações internacionais e para a preservação do equilíbrio militar entre os países. Dessa forma, com o intuito de se manter à altura dos anseios nacionais, o EB vem conduzindo de maneira prioritária um amplo Processo de Transformação, que vem contribuindo substancialmente para aprimorar todos os sistemas da Força, reduzir o hiato tecnológico em relação a outros exércitos e mitigar vulnerabilidades que atentam à manutenção dos interesses nacionais, preservando assim, o poder dissuasório da expressão militar (DCT, 2020).

Dessa maneira, as Condicionantes Doutrinárias e Operacionais (CONDOP) ${ }^{9}$, trabalhadas no âmbito do EB para a definição das características dos SMEM, são elaboradas no sentido de se ajustarem a um ambiente operacional complexo, cujo futuro é essencialmente incerto e difuso, e onde a identificação do oponente no meio da população civil é extremamente dificultada. A atualização das CONDOP, somada ao desgaste natural do material em uso e a um quadro de recursos financeiros limitados, vem exigindo nos últimos anos soluções inteligentes, sustentáveis e oportunas no gerenciamento do processo de obtenção da Nova Família de Blindados Sobre Rodas (NFBR), que é um componente chave para a transformação do EB, a fim de torná-lo apto para enfrentar as ameaças do século XXI.
Cabe salientar, contudo, que o ano de 1997 pode ser considerado o ano de origem do então Projeto GUARANI, pois foi quando se aprovaram as CONDOP em função da nova concepção doutrinária que entrava em vigor. Mais adiante, a decisão para a obtenção de uma NFBR através do vetor Pesquisa e Desenvolvimento (P\&D) do EB ocorreu no ano de 2006 (ou seja, em um momento anterior à publicação da END de 2008), e a partir dela, o Projeto GUARANI foi iniciado de fato em 2007, nas OM do Departamento de Ciência e Tecnologia $(\mathrm{DCT})^{10}$, que possui a missão de buscar o desenvolvimento e a produção de materiais, sistemas, tecnologias e serviços na área de Defesa (DCT, 2020). De lá para cá, o Projeto GUARANI passou a adaptar-se ao aperfeiçoamento dos processos de gestão e às mudanças conjunturais, particularmente das áreas econômica e de Defesa, evoluindo assim para o estágio atual, denominado Programa Estratégico do Exército (Prg EE) GUARANI, cuja abrangência é maior em comparação ao escopo inicialmente estabelecido em 2007.

\section{O Processo de Transformação do Exército}

O conceito de transformação de forças militares foi desenvolvido para possibilitar o seu ajustamento diante do aparecimento de novas tecnologias, ao mesmo tempo que busca quebrar paradigmas, que se constituem em entraves ao aprimoramento institucional. Para uma melhor compreensão da "transformação" em questão, é conveniente apontar a conceituação desse termo feita por Covarrubias (2007), que é similar à adotada atualmente no EB: "é o desenvolvimento de novas capacidades para cumprir novas missões ou desempenhar novas funções de combate." Além disso "implica numa mudança muito mais radical já que envolve mudanças nas missões e tem um alcance não somente técnico, mas também político" (p. 18). Para clarificar a diferença deste com o conceitos de modernização e adaptação, Covarrubias (2007) afirma ainda que modernização "é a otimização das capacidades para cumprir a missão de uma melhor forma", ao passo que adaptação "consiste em adaptar as estruturas existentes para continuar cumprindo com as tarefas previstas" (p. 18). Assim sendo, entende-se que uma transformação do EB não envolve somente o aperfeiçoamento da doutrina ou a obtenção de material, mas sim reflexões e mudanças em toda a estrutura e processos da Força.

Dessa maneira, em consonância com a END, atualmente é conduzido o Processo de Transformação do Exército Brasileiro, que passou a ser implementado em 2010, a partir da expedição de uma diretriz do Estado-

8 Um dos principais instrumentos do planejamento econômico para um desenvolvimento nacional equilibrado é a Estratégia Nacional de Desenvolvimento Econômico e Social (ENDES), que é "concebida com o objetivo de orientar, articular e influenciar as discussões dos demais [...] planos nacionais, setoriais e regionais [...]" (MEPDG, 2018).

9 No EB, as CONDOP de um material são reunidas em um documento de mesmo nome, com parâmetros que definem o emprego e o desempenho desse material, levando-se em consideração a Doutrina Militar Terrestre (Comandante do Exército, 2016).

10 Órgão de Direção Setorial do EB, que possui em sua organização o Centro Tecnológico do Exército (CTEx), situado no município do Rio de Janeiro. 
-Maior do Exército (EME) ${ }^{11}$, que é o órgão de direção geral da Força. Para a condução das tarefas previstas nesse processo, foram organizados grupos de trabalho relacionados aos denominados vetores de transformação: Doutrina, Educação e Cultura, Gestão e Recursos Humanos, Gestão Corrente e Estratégica, Ciência e Tecnologia (C\&T) e Modernização do Material, Preparo e Emprego e Logística.

Do ponto de vista do vetor C\&T e Modernização do Material, foco deste trabalho, o Processo de Transformação do EB "requer a adoção de medidas que criem, estimulem e potencializem as capacitações tecnológicas e produtivas nacionais, de tal forma que estas venham a dotar a Força Terrestre de CO compatíveis com a evolução das estaturas política e estratégica do Brasil" (Comandante do Exército, 2019, p. 1). Para o desenvolvimento de SMEM devidamente ajustados às necessidades operacionais da Força, é primordial também o estudo e a elaboração de uma nova Doutrina Militar Terrestre contendo um novo conceito operativo da Força, pois uma nova doutrina estabelece parâmetros de emprego, os quais serão utilizados como referência pelos desenvolvedores de SMEM. Como já mencionado, os parâmetros em questão são consolidados nas CONDOP.

Nesse sentido, em 2013, foram aprovadas pelo Chefe do EME as Bases para a Transformação da Doutrina Militar Terrestre. Este documento, além de trazer considerações a respeito dos fatores que afetam os conflitos 12 na Era do Conhecimento e as principais implicações para as operações terrestres13, apresentou a conceituação das "Operações no Amplo Espectro", conceito operativo adotado pela Força, e também as características requeridas pelos elementos da Força Terrestre nesse contexto: Flexibilidade, Adaptabilidade, Modularidade, Elasticidade e Sustentabilidade (FAMES).
Do exposto, foram estabelecidas metas para o Prg EE GUARANI que vão além da obtenção dos novos blindados. Assim, o principal objetivo estabelecido para o programa foi de "transformar a Infantaria Motorizada em Mecanizada e modernizar a Cavalaria Mecanizada". É provável que a magnitude da transformação esperada no cerne das duas Armas base do EB e o salto qualitativo e quantitativo do poder de combate da Força Terrestre, por meio do Prg EE GUARANI, só encontre paralelo nas transformações ocorridas na década de 1970, quando os regimentos de Infantaria foram transformados em batalhões de Infantaria motorizados e blindados, e os regimentos de Cavalaria em regimentos de Cavalaria blindados, de carros de combate e mecanizados, com estes últimos recebendo os blindados Cascavel e Urutu.

A condução do Prg EE GUARANI e dos demais programas é otimizada através do Portfólio Estratégico do Exército (Ptf EE), que é o principal instrumento do Processo de Transformação do EB. As Diretrizes do Comandante do Exército de 2019, que é uma orientação contextualizada para todos os integrantes da Força, aponta duas premissas fundamentais que norteiam o Ptf EE: "a continuidade do Processo de Transformação do Exército [...]; e a manutenção de elevada capacidade dissuasória fundamentada em alto nível de preparo e na incorporação de novas capacidades" (Comandante do Exército, 2019).

Entende-se como portfólio "um conjunto de subportfólios, programas e projetos desenvolvidos para permitir a implementação da estratégia da organização. Umas das principais características dos portfólios é que eles não são temporários como projetos e programas" (Comandante do Exército, 2017). No caso do EB, o Ptf EE reúne e organiza todos os programas estratégicos da Força em três subportfólios: Dimensão Humana, Geração de Força e Defesa da Sociedade (Tabela 1).

\begin{tabular}{l|l}
\hline \hline \multicolumn{1}{c}{ Portfólio Estratégico do Exército Brasileiro } \\
\hline \multirow{1}{c}{ Subportfólios } & \multicolumn{1}{c}{ Programas Estratégicos do Exército Brasileiro } \\
\hline \multirow{5}{*}{ Geração de Força } & $\begin{array}{l}\text { Força da Nossa Força (Ações para atrair, reter, motivar e comprometer o } \\
\text { pessoal) } \\
\text { Educação e Cultura }\end{array}$ \\
& Amazônia Protegida \\
& Gestão de Tecnologia da Informação e Comunicações \\
& Logística Militar Terrestre \\
& PENSE (Sistema de Engenharia do Exército) \\
& Sentinela da Pátria \\
& SISOMT - Sistema Operacional Militar Terrestre \\
\hline
\end{tabular}

11 Diretriz aprovada pela Portaria No 075 -EME, de 10 de junho de 2010.

12 A dimensão humana, o combate em áreas humanizadas, a importância da informação, o caráter difuso das ameaças, o ambiente interagências, as novas tecnologias e sua proliferação e o espaço cibernético (EME, 2013).

13 As competências requeridas, as capacidades requeridas, a letalidade seletiva, a proteção da tropa, a superioridade de informações, a consciência situacional, a digitalização do espaço de batalha, as operações de informação e a aproximação dos níveis de planejamento e condução das operações (EME, 2013). 


\begin{tabular}{l|l}
\hline \hline \multicolumn{1}{c}{ Portfólio Estratégico do Exército Brasileiro } \\
\hline \multicolumn{1}{c}{ Subportfólios } & \multicolumn{1}{c}{ Programas Estratégicos do Exército Brasileiro } \\
\hline \multirow{5}{*}{ Defesa da Sociedade } & ASTROS 2020 (Sistema de Artilharia de Mísseis e Foguetes) \\
& Aviação do Exército \\
& Defesa Antiaérea \\
& Defesa Cibernética na Defesa Nacional \\
& OCOP - Obtenção da Capacidade Operacional Plena \\
& PROTEGER - Proteção da Sociedade \\
& SISFRON - Sistema Integrado de Monitoramento das Fronteiras \\
& GUARANI \\
\hline
\end{tabular}

Tabela 1. Portfólio Estratégico do Exército e Prg EE GUARANI em destaque. (Fonte: EPEx, 2018).

No escopo do subportfólio Defesa da Sociedade, os resultados do Prg EE GUARANI, juntamente com os resultados obtidos dos demais programas, contribuem para a obtenção e o suporte das capacidades de nível mais elevado da Instituição, as denominadas Capacidades Militares Terrestres (CMT). Atualmente, o EB trabalha com nove CMT, dentre os quais Pronta Resposta Estratégica e Superioridade no Enfrentamento ${ }^{14}$. As CMT são as necessárias para que o EB possa cumprir as missões previstas para as Forças Armadas contidas na Constituição Federal brasileira de 1988. Para fins de preparo e emprego, cada CMT agrupa um determinado número de $\mathrm{CO}$ afins e com ligações funcionais, possibilitando dessa maneira, que cada uma delas seja melhor desenvolvida. As estratégias para a obtenção das CMT e a correlação delas com os Prg EE são consolidadas no Plano Estratégico do Exército (PEEx).

O ente responsável pelo planejamento, coordenação e integração das atividades de interesse do Ptf EE é o Escritório de Projetos do Exército (EPEx) ${ }^{15}$, integrante do EME. O EPEx "é o órgão de coordenação executiva do EME para fins de gerenciamento do Ptf EE, constituindo-se no escritório de projetos de mais alto nível da Força" (Comandante do Exército, 2017), e tem como atribuição a identificação de pontos de convergência entre os diversos programas do portfólio com vistas a otimizar processos e a racionalizar os recursos financeiros. O EPEX realiza ainda o estudo das lições aprendidas e das boas práticas de todas as iniciativas relacionadas, buscando a melhoria da gestão de um modo geral (EME, 2018).
Um aspecto de relevância da gestão do Portfólio é a sua contribuição para a Base Industrial de Defesa (BID) brasileira, pois incentiva a $\mathrm{P} \& \mathrm{D}$, a transferência de tecnologias e a capacitação técnica especializada, assegurando dessa maneira "que o atendimento das necessidades de equipamento das Forças Armadas se apoie em tecnologias sob domínio nacional" (EME, 2018, p. 22). Promove ainda o desenvolvimento das tão necessárias tecnologias de emprego dual, que são uma excelente opção quando se trata de otimizar e justificar investimentos públicos em SMEM.

Neste ponto é necessário novamente mencionar o DCT e o seu papel para o desenvolvimento da BID do País. O DCT gere uma ferramenta chamada Sistema Defesa, Indústria e Academia de Inovação (SisDIA) ${ }^{16}$, cujo funcionamento tem como base os conceitos da Inovação Aberta ${ }^{17}$ e da Tríplice Hélice, cuja definição foi concebida pelos professores Henry Etzkowitz e Loet Leydesdorff, e se fundamenta na interação entre as instituições universitárias, as organizações empresariais que representam o setor produtivo de bens e serviços, e as instâncias governamentais, que são os agentes reguladores e de fomento da atividade econômica. Essa interação visa a produção de novos conhecimentos, a inovação científica e tecnológica e o desenvolvimento econômico. O SisDIA (Figura 1) funciona sob esse contexto (DCT, 2020) e tem como referência os Objetivos Nacionais de Defesa da PND atinentes à inovação e tecnologia.

14 Conforme o Catálogo de Capacidades do Exército, as CMT são: Pronta Resposta Estratégica, Superioridade no Enfrentamento, Apoio a Órgãos Governamentais, Comando e Controle, Sustentação Logística, Interoperabilidade, Proteção, Superioridade de Informações e Cibernética (EME, 2015).

15 O EPEx foi implementado por meio da Portaria No 134-EME, de 10 de setembro de 2012.

16 De fato, o SisDIA é conduzido pela Agência de Gestão e Inovação Tecnológica (AGITEC), organização militar subordinada ao DCT (DCT, 2020).

17 Inovação aberta é um paradigma desenvolvido por Henry William Chesbrough, professor da Universidade da Califórnia, Estados Unidos. De modo sintético é o uso intencional de entradas de conhecimento para acelerar a inovação interna de uma organização e saídas (de conhecimento) para expandir os mercados visando o uso externo da inovação (Chesbrough, 2006, p. 2). 


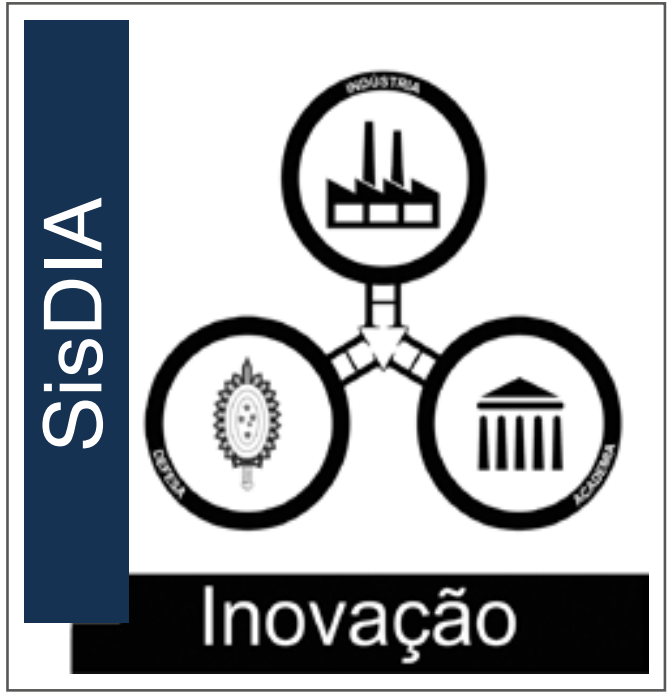

Figura 1. Logo do SisDIA, fundamentado no conceito da Tríplice Hélice. (Fonte: site do DCT, 2020).

Atualmente, dentro do escopo do SisDIA, estão em desenvolvimento tecnologias e capacidades relacionadas à diversas áreas de pesquisa, como sensoriamento para vigilância terrestre e aérea; guiamento de mísseis e foguetes; cibernética; simuladores; Comando e Controle $\left(\mathrm{C}^{2}\right)$; embarcações blindadas e desenvolvimento, aquisição e revitalização de veículos blindados.

Assim, o processo de obtenção da NFBR no escopo do Prg EE GUARANI contempla uma variedade de meios mecanizados e seus respectivos sistemas de armas com capacidade de letalidade seletiva, e também um flexível sistema de $\mathrm{C}^{2}$, permitindo o seu emprego em Operações no Amplo Espectro dos conflitos armados. Em atenção às suas CONDOP, dela fazem parte duas subfamílias: uma média de veículos blindados de tração 6x6 e 8x8 (esta última concebida para operações de reconhecimento), e uma leve de veículos blindados de tração $4 \times 4$, os quais devem possuir um índice de nacionalização superior a 60\% (EPEx, 2018, p. 27).
A primeira das versões do veículo $6 \times 6$ produzida foi a Viatura Blindada de Transporte de Pessoal, Média Sobre Rodas (VBTP-MSR) GUARANI. O seu projeto é determinante para o Prg EE GUARANI, e consequentemente para o Ptf EE e para o Processo de Transformação do Exército, na medida em que os novos blindados são distribuídos às unidades mecanizadas. De igual maneira, o Prg EE GUARANI, por sua importância estratégica e simbolismo, vem contribuindo substancialmente para o desenvolvimento da BID.

\section{O Plano Estratégico do Exército}

De quatro em quatro anos, com a finalidade de orientar o processo dos investimentos da Força, é elaborado o PEEx, documento da mais alta relevância institucional, pois associa os Objetivos Estratégicos do Exército (OEE) com os programas do Ptf EE. Esse plano é elaborado pelo EME através do chamado Sistema de Planejamento Estratégico do Exército (SIPLEx), um macroprocesso alinhado com o Marco Legal brasileiro, o Processo de Transformação e as diretrizes do Comandante do Exército. O SIPLEx é dividido em 7 fases (Figura 2) e tem início com a compreensão exata da Missão do EB, e também a apresentação dos Valores e da Visão de Futuro da Força.

Na sequência, é conduzida a fase de Análise Estratégica, com a participação do Centro de Estudos Estratégicos do Exército (CEEEx), que tem a responsabilidade de avaliar as conjunturas nacional e internacional, além de conduzir estudos prospectivos de interesse do EB. Essas ações contribuem para a elaboração de um diagnóstico estratégico e de cenários prospectivos, que possibilitam a identificação de possíveis situações em que haja a necessidade de ações oportunas da Força para a superação de óbices e aproveitamento de oportunidades. O CEEEx mantém ainda ligação com órgãos similares do MD, das demais forças singulares e entidades públicas e privadas, incluindo representantes do meio acadêmico e empresarial (CEEEx, 2019).

\section{SIPLEX}

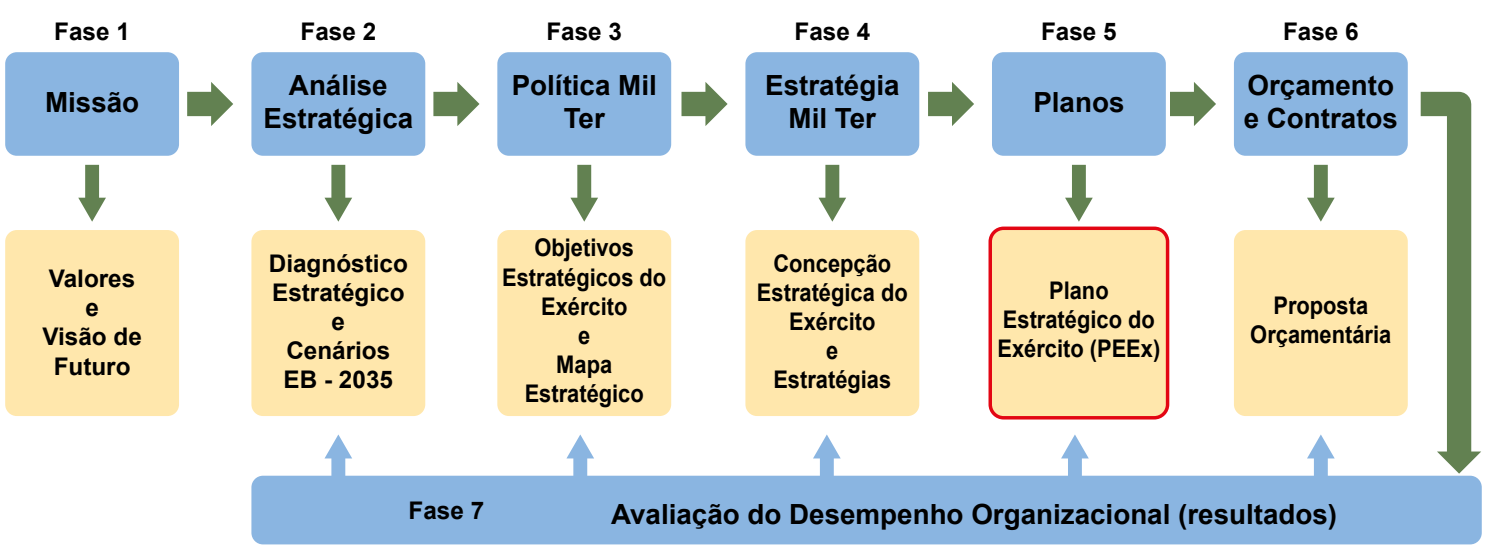

Figura 2. Versão simplificada do SIPLEx com o PEEx em destaque. (Fonte: EME). 
A Fase 3 do SIPLEx trata da elaboração da Política Militar Terrestre (PMT), cujo conteúdo tem como referência a END, efetivando assim, o alinhamento desejado com as políticas e diretrizes emanadas do MD. Além desse aspecto, a PMT é decorrente da análise da Missão do EB e do estudo das indicações resultantes da Análise Estratégica, sendo norteado pela Visão de Futuro da Força. A PMT é o documento de mais alto nível do Comando do EB e tem como finalidade principal orientar os trabalhos de elaboração da Concepção Estratégica (CE) do Exército e do PEEx. Nessa fase são relacionados pela primeira vez no processo os OEE, que traduzem de forma ampla as prioridades estratégicas da Força, orientando todos os seus componentes para a ação e para o que precisa ser feito (EME, 2019). Nesse sentido, esses objetivos são descritos e recebem um diagnóstico conjuntural simplificado. É apresentada também a intenção do Comando do Exército em relação a cada OEE, sendo apontados os fatores críticos de sucesso e os respectivos indicadores e metas a serem atingidos. Ressalta-se que na PMT, os OEE são apenas apresentados e descritos. A abordagem de como serão trabalhados e relacionados com as CMT e os Prg EE aparecerá mais adiante, na Fase 5 do SIPLEx, que corresponde ao PEEx. Na PMT aprovado em 2019, foram apresentados quinze OEE.

Ressalta-se que é acrescido à PMT um importante documento de apoio: o Mapa Estratégico do Exército, que nada mais é do que um diagrama que representa visualmente as relações de causa e efeito entre os OEE e quatro perspectivas: da sociedade, dos processos críticos, do aprendizado e crescimento, e da institucional $^{18}$ (EME, 2019). Além disso, um aspecto relevante do Mapa Estratégico é a sua vinculação ao Ptf EE, cujo alinhamento estratégico dos seus programas com os OEE permitirão “a maximização dos benefícios e a otimização na alocação integrada dos recursos (financeiros), configurando o portfólio como ferramenta efetiva na implantação da estratégia de mais alto nível da Força" (Comandante do Exército, 2017).

A Fase 4 do SIPLEx é a Estratégia Militar Terrestre, em que é elaborada a CE do Exército, um embasamento conceitual que apresenta como o emprego do EB é pensado. Para isso, apresenta também a visualização da organização, articulação e o preparo da Força Terrestre, destacando as suas prioridades. Completando as atividades dessa fase, cada um dos OEE são desmembrados em estratégias e ações estratégicas, de modo a possibilitar a correlação desses elementos com a obtenção da CMT e com o Prg EE, a ser realizada na fase seguinte.

Nesse ponto, todos os elementos necessários para elaboração do PEEx já foram apresentados, e dessa maneira, é iniciada a Fase 5, que consolidará os OEE, apontando os prazos para que as respectivas atividades sejam executadas. Ademais, com o objetivo de tornar possível o manejo dos OEE e seus desdobramentos pelos órgãos de direção setorial do EB e pelos comandos militares de área, é feito o relacionamento de cada um deles com as respectivas CMT a serem obtidas e os Prg EE envolvidos, bem como a indicação do ente responsável ou que tenha algum interesse na sua execução. O PEEx é produzido para que abarque um período de 4 anos, de modo que seus prazos sejam coincidentes como as do Plano Plurianual (PPA) ${ }^{19}$ do Governo Federal, previsto no artigo 165 da Constituição Federal. A atual versão do PEEx foi aprovada em dezembro de 2019 e corresponde ao quadriênio 2020-2023. Nesse plano estão relacionados os OEE com as suas respectivas estratégias e ações estratégicas decorrentes. Na Tabela 2, estão indicados os OEE que possuem relação direta com o Prg EE GUARANI, e em qual CMT é esperado o efeito da condução das estratégias associadas.

\begin{tabular}{|c|c|c|}
\hline OEE & Estratégia & CMT \\
\hline \multirow{2}{*}{$\begin{array}{l}\text { Contribuir com a Dissuasão } \\
\text { Extrarregional }\end{array}$} & Ampliação da Capacidade Operacional & \multirow{3}{*}{$\begin{array}{l}\text { Superioridade } \\
\text { no } \\
\text { Enfrentamento }\end{array}$} \\
\hline & Ampliação da mobilidade e elasticidade da Força & \\
\hline $\begin{array}{l}\text { Aperfeiçoar o Sistema de } \\
\text { Ciência, Tecnologia e Inovação }\end{array}$ & $\begin{array}{l}\text { Pesquisa, Desenvolvimento e Inovação de Produtos de } \\
\text { Defesa }\end{array}$ & \\
\hline $\begin{array}{l}\text { Manter atualizado o Sistema de } \\
\text { Doutrina Militar Terrestre }\end{array}$ & $\begin{array}{l}\text { Estabelecimento de uma Doutrina Militar Terrestre } \\
\text { compatível com uma Força transformada }\end{array}$ & \multirow{2}{*}{ Todas } \\
\hline $\begin{array}{l}\text { Aperfeiçoar o Sistema de } \\
\text { Educação e Cultura }\end{array}$ & Adequação da infraestrutura de Educação e Cultura & \\
\hline
\end{tabular}

Tabela 2. OEE relacionados ao Prg EE GUARANI. (Fonte: EME).

18 O Mapa Estratégico do Exército é apresentado a partir de uma adequação da metodologia Balanced Scorecard (BSC), que é empregada em planejamento e gestão de organizações para a implementação de uma estratégia. A metodologia BSC emprega quatro perspectivas: a financeira, a dos clientes, a dos processos internos e a do aprendizado e crescimento.

19 Instrumento de planejamento de médio prazo elaborado pelo Ministério da Economia que define as diretrizes, objetivos e metas da administração pública federal para um horizonte de quatro anos (MEPDG, 2020). 
O PEEx 2020-2023, tendo como base a CE, aponta também a prioridade para recomplemento de SMEM das grandes unidades da Força Terrestre. Assim, verifica-se a alta prioridade dada à duas grandes unidades localizadas nos trechos sul e oeste da faixa de fronteira brasileira: a $15^{\text {a }}$ Brigada de Infantaria Mecanizada $\left(15^{\mathrm{a}}\right.$ Bda Inf Mec) e a $4^{\text {a }}$ Brigada de Cavalaria Mecanizada (4 $\left.{ }^{\mathrm{a}} \mathrm{Bda} \mathrm{C} \mathrm{Mec}\right)$. Essas duas brigadas, enquadradas como Forças de Emprego Estratégico, são consideradas essenciais nos processos do Prg EE GUARANI, evidenciando assim, a busca pelo atingimento do principal objetivo do programa em questão.

A penúltima fase do SIPLEx é a execução da Proposta Orçamentária e a celebração dos contratos de objetivos entre os diversos órgãos envolvidos na execução do PEEx. Cabe ressaltar que as restrições orçamentárias representam um óbice de relevância à execução do PEEx 2020-2023 e, em consequência, ao Processo de Transformação do Exército. Dessa maneira, foi reduzida a quantidade de atividades necessárias para a efetivação das estratégias (e ações estratégicas) dos OEE. Contudo, devido à sua importância para a obtenção de determinadas CMT, algumas atividades consideradas fundamentais e de alto custo foram mantidas no PEEx. Esse é o caso das atividades relacionadas ao Prg EE GUARANI, que como já foi visto, é um dos aspectos chave no Processo de Transformação do Exército (EME, 2019). Encerrando o SIPLEx, é conduzida a Avaliação do Desempenho Organizacional que é conduzida durante toda a vigência do PEEx, analisando os resultados obtidos das fases posteriores com a finalidade de aperfeiçoar a gestão do sistema.

\section{A Gestão do Programa Estratégico do Exército Guarani}

A solução adotada, voltada para o desenvolvimento de uma NFBR, foi acompanhada também pela decisão de modernização de parcela dos Urutus e Cascavéis. Assim, em um contexto de recursos orçamentários restritivos, a solução em pauta seguiu por um caminho situado entre as duas situações mencionadas, pois um aspecto fundamental a ser considerado é o longo prazo exigido para o desenvolvimento do Prg EE GUARANI, com os lotes de novos veículos sendo entregues em diversas etapas no decorrer de um longo período. Atualmente, a modernização dos antigos meios mecanizados está sendo conduzida no Arsenal de Guerra de São Paulo em parceria com uma empresa civil. Essa solução mista proporciona a manutenção da operacio- nalidade da tropa enquanto se conduz o processo gradual de substituição dos veículos.

Como já mencionado, os programas estratégicos, dentre os quais o Prg EE GUARANI, fazem parte do Ptf EE, que é gerenciado pelo EPEx por meio de outro macroprocesso, denominado Macroprocesso da Gestão do Portfólio do Exército, que entrou em vigor em fevereiro de $2017^{20}$, por ocasião da aprovação das inéditas Normas para Elaboração, Gerenciamento e Acompanhamento do Portfólio e dos Programas Estratégicos do Exército Brasileiro (NEGAPORT-EB). O gerenciamento de projetos não é algo recente no $\mathrm{EB}$, entretanto no prefácio das normas em questão, é feita uma consideração sobre o ineditismo de gerenciar programas estratégicos no EB formatados segundo o conteúdo baseado e adaptado do Guia PMBoK - Project Management Body of Knowledge, do Project Management Institute (PMI), que é considerado uma referência internacional para o gerenciamento de projetos (Comandante do Exército, 2017). Ainda nesse sentido, é feito o seguinte apontamento:

Considerando o nível e a complexidade dos Prg EE, não se pode deixar de estudar o que o referencial teórico acadêmico-corporativo apresenta. Contudo, mesmo observando-se que as forças armadas de outros países, que gozam de respeito no sistema internacional, também se valem destes mesmos conhecimentos, estas normas levaram em conta a cultura institucional e a realidade do EB (Comandante do Exército, 2017).

Ressalta-se que como o atual Prg EE GUARANI evoluiu de um projeto menos abrangente iniciado em $2007^{21}$, ou seja, anterior à adoção das NEGAPORT-EB, necessitando, assim, passar por diversos ajustes para se adequar às referidas normas, a começar pela própria designação, já que projeto e programa possuem definições distintas. Segundo as NEGAPORT-EB, Prg EE é um grupamento de "projetos e ações complementares relacionados, que são gerenciados de modo coordenado para a obtenção de benefícios e controle que não seriam disponibilizados se seus componentes fossem gerenciados individualmente" (Comandante do Exército, 2017, p. 12), objetivando assim ao atendimento dos OEE. Por sua vez, Projeto Estratégico (do Exército) "é um esforço temporário empreendido para criar um produto, serviço ou resultado que atende diretamente a, no mínimo, um dos OEE definidos no PEEx, e que, por essa razão, deve estar diretamente vinculado ao Ptf EE" (Comandante do Exército, 2017, p. 12). Nesse sentido ainda, cabe destacar o seguinte entendimento sobre o

20 Com a publicação na Portaria No 054 do Comandante do Exército, de 30 de janeiro de 2017.

21 O Projeto GUARANI, que evoluiu para o atual Prg EE GUARANI, foi iniciado no mesmo ano em que foi aprovada a $1^{\text {a }}$ edição das Normas para Elaboração, Gerenciamento e Acompanhamento de Projetos no Exército Brasileiro (NEGAPEB). O desenvolvimento desse projeto pioneiro incluiu a reunião decisória da NFBR (marco inicial do projeto); a elaboração do projeto preliminar, modelo de inovação e seleção da empresa parceira; o desenvolvimento do protótipo; e a experimentação doutrinária (CCOMSEX, 2015, pp. 26-29). 
termo "benefício", constante na definição de Prg EE: "é um resultado da aplicação de capacidades obtidas ou aperfeiçoadas, de ações, comportamentos, produtos ou serviços que criam valor para a organização. $\mathrm{O}$ benefício alcançado contribui para um ou mais objetivos estratégicos" (Comandante do Exército, 2017, p. 12).

O Macroprocesso da Gestão do Ptf EE é formado por quatro grupos de processos, a saber: de Definição, de Planejamento, de Execução e de Controle (Figura 3). Sob coordenação executiva do EPEx, esse macroprocesso é iniciado com a análise do PEEx. Dessa análise, de caráter multisetorial ${ }^{22}$, são identificadas as lacunas de $\mathrm{CO}$ que necessitam a criação de um projeto/programa estratégico. A partir daí, são iniciadas as atividades relacionadas ao Grupo de Processos de Definição, que visa definir, avaliar, selecionar, e autorizar, ou não, a inclusão de um novo projeto/programa no Ptf EE. Na última etapa desse grupo de processos, é elaborada e aprovada a Diretriz de Implantação do novo Projeto/Programa Estratégico do Exército, dando continuidade ao macroprocesso em questão, ao mesmo tempo que dá início ao processo de ciclo de vida de um programa, no caso, o Prg EE GUARANI (em azul na Figura 3).

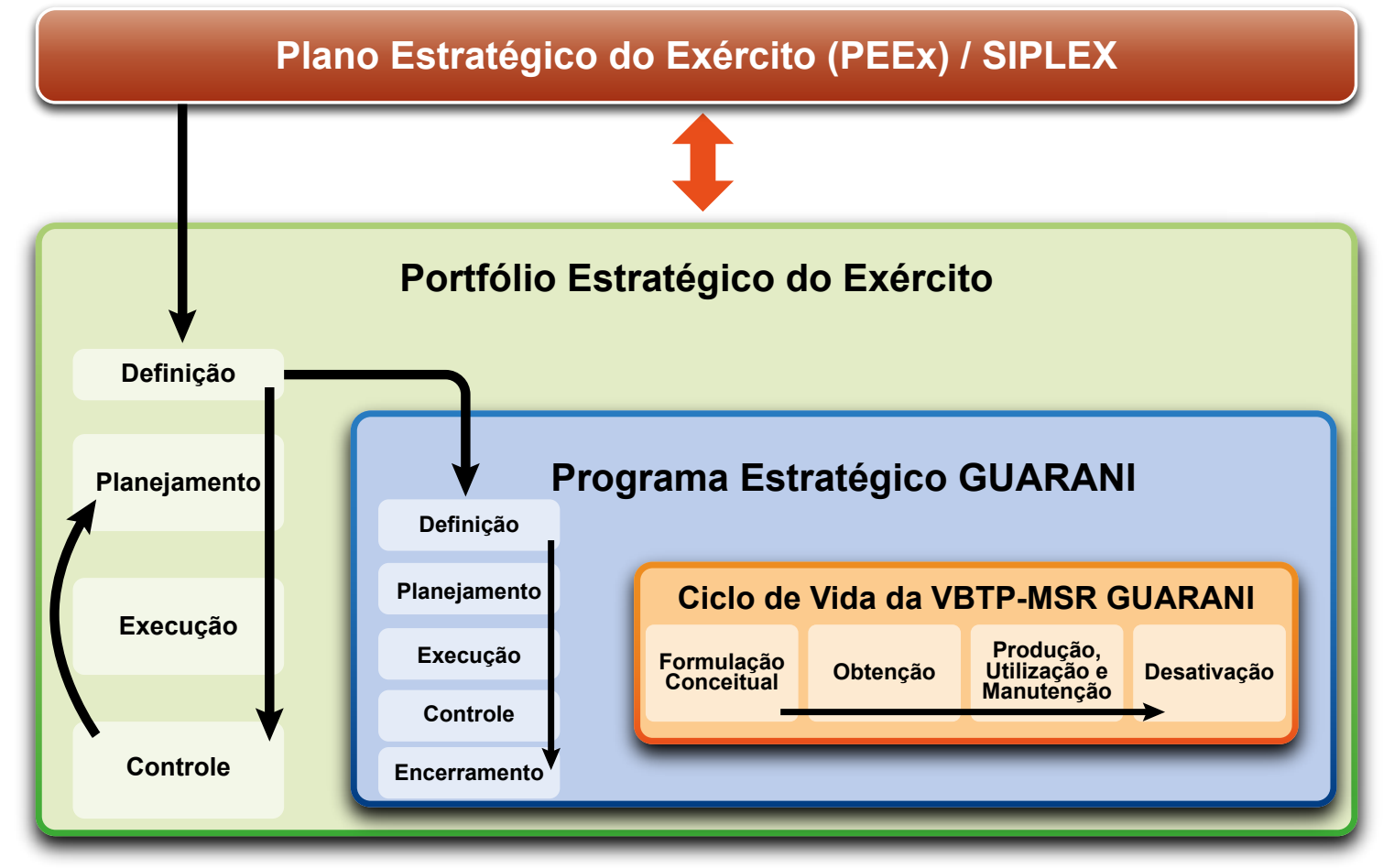

Figura 3. Macroprocesso de Gestão do Ptf EE. (Fonte: o autor).

$\mathrm{Na}$ sequência, são conduzidas as atividades do Grupo de Processos de Planejamento, cujo objetivo é desenvolver e aprovar o Plano de Gerenciamento do Portfólio; do Grupo de Processos Execução, cujo objetivo, como o próprio nome indica, é executar as ações previstas no plano produzido na fase anterior; e por fim, do Grupo de Processo de Controle, que visa realizar o acompanhamento e controle do portfólio e gerenciar as mudanças identificadas como necessárias no plano original, que são apresentadas e inseridas no Grupo de Processos de Planejamento, realimentando, assim, o Macroprocesso de Gestão do Ptf EE. Esse ciclo não possui duração estipulada, entretanto é evidente a importância da sua sincronização com o PEEx. Ressalta-se também que os processos que compõem esses três grupos apresentam vários pontos de contato com os processos correspondentes aos ciclos de vida dos Prg EE. Dessa maneira são efetivadas entradas e saídas em ambos os sentidos dos processos, mantendo o alinhamento estratégico desejado e os planos e outros documentos atualizados.

Por sua vez, a duração do ciclo de vida de um Prg EE varia de acordo com a complexidade das ações a serem conduzidas. Um Prg EE, conforme o Art. 90 das NEGAPORT, "pode ter uma duração muito longa (décadas), portanto não compensa detalhar todas as suas atividades, sob pena de se ter um planejamento falho, que fatalmente terá que ser modificado várias vezes ao longo do ciclo de vida desse programa" (Comandante

22 Refere-se, de uma maneira geral, ao trabalho desenvolvido em conjunto pelo EME, pelo Comando de Operações Terrestres (COTER), pelos Órgãos de Direção Setorial (ODS) e/ou pelos Comandos Militares de Área. 
do Exército, 2017, p. 51). Dessa maneira, os planejamentos dos Prg EE, dentre eles os do Prg EE GUARANI, são concebidos e executados em parcelas/ciclos de 4 anos, buscando-se coerência com o PPA do Governo Federal, que como já foi apontado neste trabalho, também é utilizado como referência para o estabelecimento da vigência do PEEx.

O ciclo de vida de um Prg EE é composto pelas seguintes fases: Definição, Planejamento ${ }^{23}$, Execução, Controle e Encerramento. Conforme mencionado anteriormente, um Prg EE é iniciado por meio de uma Diretriz de Implantação do novo Programa Estratégico do Exército. A diretriz referente ao Prg EE GUARANI foi aprovada em $2018^{24}$, em substituição a uma de 2013, com a finalidade de regular as medidas necessárias à implantação do programa em questão. Essa diretriz e outros documentos relacionados à iniciação e à viabilidade do programa são reunidos no Grupo de Processo de Definição do Prg EE e servem de subsídio para o planejamento da condução do programa propriamente dito. Nesse planejamento, o foco durante as atividades posteriores pode ser obtido através de um mapa de benefícios, que relaciona as entregas visualizadas do programa com o desenvolvimento das capacidades necessárias, que são as $\mathrm{CO}$ já mencionadas. A partir dessas capacidades, é feita a associação com os benefícios pretendidos, que permitirão atender a um ou mais OEE (Comandante do Exército, 2017, p. 56). Na sequência, são conduzidas as etapas de Execução e Controle, e por fim o Encerramento do programa.
Ressalta-se que as tarefas referentes aos Grupos de Processos Planejamento, Execução e Controle, possuem enlaces com a Gestão do Ciclo de Vida dos Sistemas e Materiais de Emprego Militar, um processo previsto em uma publicação especifica ${ }^{25}$. Neste trabalho, dentro do Prg EE GUARANI, o SMEM evidenciado é a VBTP-MSR 6x6 GUARANI. Neste ponto, cabe ressaltar, mais uma vez, a amplitude já citada do programa em análise, que vai além do processo de obtenção da nova viatura. De acordo com o Ptf EE em vigor e com a sua diretriz de implantação, o Prg EE GUARANI é composto por quatro projetos e cinco ações complementares (Figura 4), que englobam Pesquisa e Desenvolvimento de Material e iniciativas relacionadas ao aperfeiçoamento dos sistemas de gestão, à capacitação e ao preparo da tropa, à implementação de um suporte logístico integrado e à construção de infraestrutura, como pavilhões de manutenção e garagens, visando a adequação das OM mecanizadas. Além disso, a área de emprego e capacitação de pessoal forma operadores e mecânicos para todas as funções a bordo e em todos os escalões de manutenção. Todas essas ações convergem para o atingimento da plena capacidade de mecanização da Força (EPEx, 2018, p. 28). O Prg EE GUARANI inclui ainda a integração de sistemas de armas e de $\mathrm{C}^{2}$, a experimentação doutrinária e a obtenção de sistemas de simulação, contemplando dessa maneira, o emprego desde o escalão subunidade até o nível brigada.

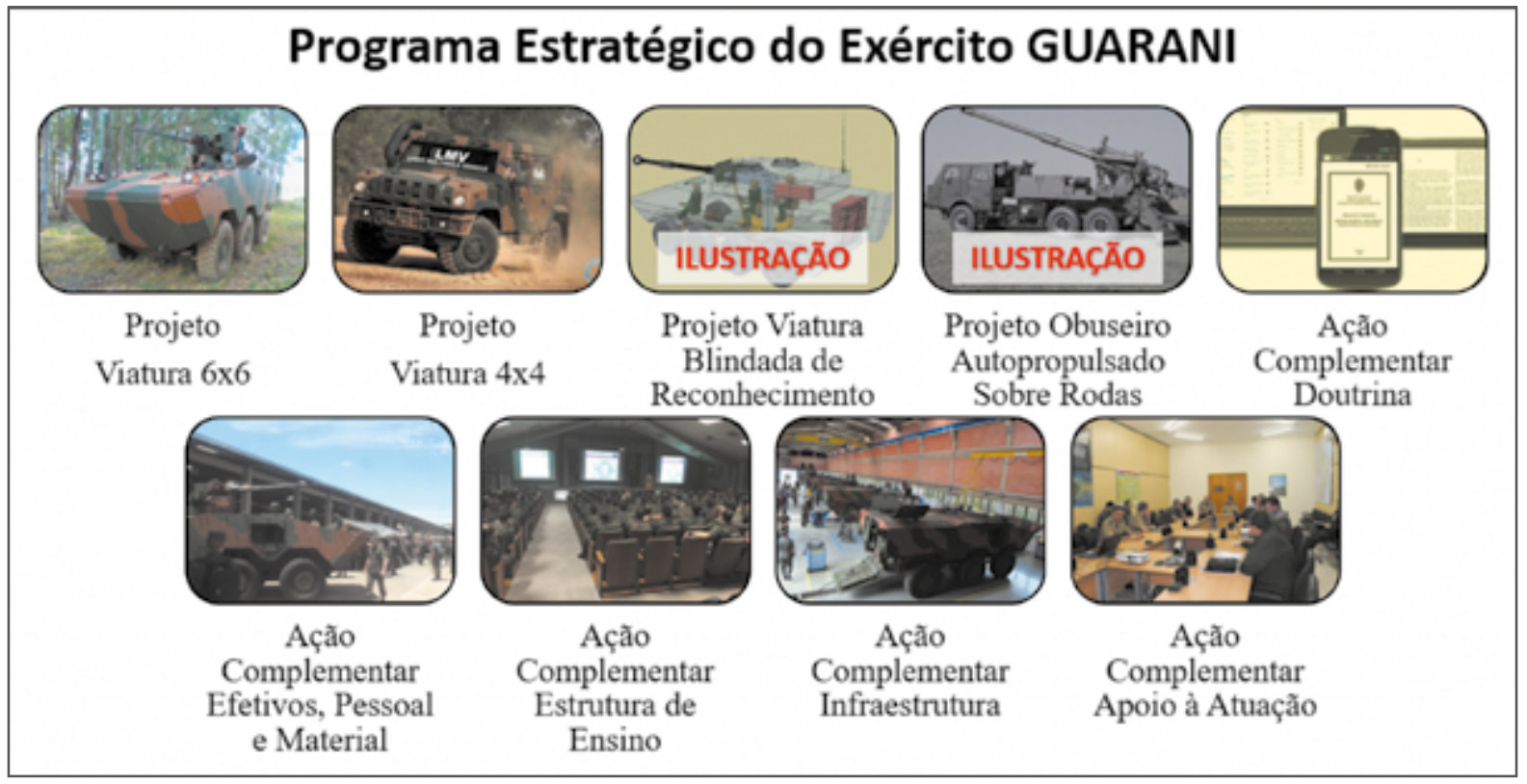

Figura 4. Composição do Prg EE GUARANI. (Fonte: EME).

23 O Grupo de Processos de Planejamento do ciclo de vida de um Prg EE de duração muito longa, também inclui o planejamento por tranche, que é a parte do programa que será executada de fato após o planejamento e, por conseguinte, é a parcela que deve ser detalhada. Dessa maneira, todo o Prg EE é visualizado, mas apenas a tranche a seguir será detalhada para execução (Comandante do Exército, 2017, p. 51). Para uma exposição mais sucinta do processo em questão, esse aspecto foi suprimido do texto.

24 Aprovada pela Portaria No 255-EME, de 30 de outubro de 2018.

25 Instruções Gerais para a Gestão do Ciclo de Vida dos Sistemas e Materiais de Emprego Militar (EB10-IG-01.018), $1^{\text {a }}$ Edição, 2016. 
Dentre os projetos e ações complementares do Prg EE GUARANI, o Projeto da Viatura 6x6 pode ser considerado o cerne do programa por ser o que atualmente mais benefícios está trazendo, tanto para a Força Terrestre como para a sociedade. Como já apontado, a BID brasileira vem sendo fortemente beneficiada pelo projeto em questão. Essa consideração é observada na condução do Ciclo de Vida da VBTP-MSR GUARANI, que já passou pelas duas primeiras fases, e atualmente, está na fase de Produção, Utilização e Manutenção. Na Fase de Formulação Conceitual, iniciada em 2007, foram elaborados os requisitos técnicos básicos, o anteprojeto e o estudo de viabilidade técnico-econômica da $\mathrm{NFBR}^{26}$, que consubstanciaram a condução da $1^{\mathrm{a}}$ reunião preparatória para a obtenção da NFBR. Face à complexidade do projeto, foi exclusivamente criada para conduzi-lo uma gerência técnica, que concebeu o modelo de inovação a ser seguido, e resultou na seleção da Fiat S/A como a empresa parceira, por meio da sua divisão Iveco ${ }^{27}$ (CCOMSEX, 2015, pp. 27-28). Em agosto de 2012, já na Fase de Obtenção, ocorreu a assinatura do contrato de aquisição do lote de experimentação doutrinária, composto por 86 VBTP-MSR GUARANI, de um total previsto de mais de 1.500 viaturas planejadas para serem distribuídas para aproximadamente 100 OM da Força Terrestre até o final do programa (CCOMSEX, 2012).

\section{Resultados Obtidos até o Momento Atual}

Como já mencionado, o objetivo principal do Prg EE GUARANI é transformar as Brigadas de Infantaria Motorizada em Mecanizada e modernizar as Brigadas de Cavalaria Mecanizada. Para tanto, o desenvolvimento da NFBR com tecnologia nacional, constitui-se no eixo principal do programa. Desde o seu início, já foram entregues até meados de 2019, mais de 400 unidades da VBTP-MSR GUARANI (CCOMSEX, 2019).

A versão básica da VBTP-MSR adquirida pelo EB apresenta como características básicas: peso de 18 toneladas, autonomia de $600 \mathrm{Km}$ e tração nas seis rodas, sendo esterçáveis os dois eixos dianteiros, diminuindo restrições de arrasto nas rodas, melhorando a distribuição de peso e reduzindo o raio de giro, possibilitando assim, manobras em espaços mais reduzidos, como no interior de centro urbanos. Sua potência e versatilidade são obtidos por meio de um motor diesel Cursor 9 de 383 cavalos, que permite ao veículo atingir velocidades de $90 \mathrm{Km} / \mathrm{h}$, e de uma transmissão automática de 6 velocidades à frente. $\mathrm{O}$ motor funciona com diesel, querosene de aviação ou com a combinação de ambos em qualquer proporção, tornando o blindado adaptável à diversas situações. Outro destaque são os pneus run flat, montados com anel toroidal, que conseguem rodar sem pressão pneumática (DCT, s.d.).

A VBTP-MSR GUARANI foi concebido ainda para transportar até 11 militares e ultrapassar rampas frontais de $60 \%$ de inclinação, rampas laterais de 30\% e obstáculos com até $0,5 \mathrm{~m}$ de altura. Suas dimensões não são exageradas, tendo 7,04 $\mathrm{m}$ de comprimento, 2,70 $\mathrm{m}$ de largura e 2,34 $\mathrm{m}$ de altura, permitindo assim ser embarcado e transportado em aeronaves como o C-130 Hércules e o C-390 Millennium da EMBRAER. Sua baixa silhueta também diminui a exposição da guarnição em situações de risco. Por ser anfíbio, pode se deslocar em meio aquático por meio de dois propulsores de hélices. Possui ainda ambiente interno climatizado, ergonomia adequada para os tripulantes, sistema de detecção e extinção de incêndio, capacidade de operar no período noturno e posicionamento global por satélite (GPS) (DCT, s.d.).

Destaca-se também a incorporação dos conceitos de adaptabilidade e modularidade no projeto, características imprescindíveis para as forças militares modernas, permitindo que o veículo seja configurado de diversas maneiras de acordo com a necessidade de determinada tropa ou situação. Nesse sentido, o veículo sai de fábrica com uma proteção blindada básica composta por chapas metálicas de $30 \mathrm{~mm}$ antiminas, capazes de proteger a guarnição de modo efetivo contra disparos de munição 7,62 $\mathrm{mm} \mathrm{M1}$, possibilitando o emprego seguro do veículo na maioria das situações de crise e conflito verificados atualmente, particularmente aqueles verificados na América do Sul nos últimos anos. Nas situações em que se visualiza enfrentamentos mais intensos e a utilização de armamento mais pesado, a viatura GUARANI já é devidamente preparada para receber blindagem adicional, ampliando significativamente as suas opções de emprego. Além da modularidade quanto à proteção, o seu design permite a incorporação de diferentes torres, armas, sensores e sistemas de comunicações em um mesmo veículo.

Sem a necessidade de alteração nenhuma no projeto, o veículo pode ser adaptado para receber tanto reparos automatizados como manuais, permitindo o emprego de metralhadoras de calibres 7,62 mm e .50, além de um canhão de $30 \mathrm{~mm}$. Dentre as versões já entregues, chama a atenção a VBTP-MSR equipada com os Reparos de Metralhadoras Automatizadas X (REMAX) com metralhadoras .50. Ademais, a operação do armamento é feita remotamente a partir do interior do veículo, contando ainda com um sistema de mira laser que, quando ativo, direciona automaticamente a torre do reparo, alinhando-o na direção do alvo desejado (DCT, s.d.).

26 Atividades conduzidas pelo Centro Tecnológico do Exército (CTEx), subordinado ao DCT.

27 A unidade fabril da Iveco Veículos de Defesa foi instalada na cidade de Sete Lagoas, estado de Minas Gerais. 
Além da obtenção da VBTP-MSR 6x6 GUARANI e a aquisição recente da Viatura Blindada Multitarefa Leve de Rodas (VBMT-LSR), 4x4, também da Iveco, as outras entregas previstas no escopo do Prg EE GUARANI são as versões da VBTP-MSR com implemento de Engenharia e com morteiro, a Viatura Blindada de Reconhecimento (VBR), munições e a capacitação de pessoal para o emprego dos novos SMEM (EPEx, 2019).

No decorrer da execução dos diversos programas que integram o Ptf EE, é natural a ocorrência de ajustes no cronograma em função de fatores diversos, dos quais o principal é a disponibilidade orçamentária. Atualmente, o prazo de encerramento das obtenções do Prg EE GUARANI foi ajustado de 2030 para o ano de 2040. No curto prazo, correspondente ao período do PEEx 2020-2023, a previsão é a aquisição, por ano, de sessenta unidades da VBTP-MSR GUARANI com sistemas de $\mathrm{C}^{2}$ e de armas integrados e de oito unidades da VBMT-LSR 4x4, com todos os seus sistemas integrados (EPEx, 2019).

A magnitude dessa transformação no cerne das duas Armas base do EB já vem sendo verificada nas suas brigadas mecanizadas em função da adoção de novos manuais de campanha e na logística, com consequências imediatas para o preparo e emprego da tropa e para as estratégias de atuação da Força Terrestre, particularmente nas Operações de Faixa de Fronteira e nas Operações de Garantia da Lei e da Ordem.

\section{Emprego Dos Novos Meios}

A grande unidade escolhida para ser a pioneira no processo de transformação da Infantaria Motorizada foi a $15^{\mathrm{a}}$ Bda Inf Mec, sediada na cidade de Cascavel, estado do Paraná. Constituída por três batalhões de infantaria mecanizados, um esquadrão de cavalaria mecanizado e unidades e subunidades de apoio ao combate e de apoio logístico, todos mecanizados, a $15^{\mathrm{a}}$ Bda Inf Mec foi a grande unidade escolhida para conduzir as atividades relacionadas à Experimentação Doutrinária. Em tempo de paz, essa brigada tem como responsabilidade atuar, em coordenação e cooperação com órgãos policiais e outras agências, contra crimes transfronteiriços em uma extensa parcela da faixa de fronteira brasileira, que inclui a complexa e bastante povoada região da Tríplice Fronteira Argentina - Brasil - Paraguai, onde o crime organizado é a principal ameaça. Da mesma maneira que a sua vizinha de sul, a $4^{\mathrm{a}} \mathrm{Bda} \mathrm{C}$ Mec é a ponta de lança do Comando Militar do Oeste ${ }^{28}$ nas Operações de Faixa de Fronteira conduzidas na sua área de responsabilidade, e vem recebendo alta prioridade no processo de recompletamento de SMEM, com destaque para as VBTP-MSR GUARANI.
Cabe salientar que todas as fases do Prg EE GUARANI são concebidas de modo a buscar a integração com os demais Prg EE constantes no Ptf EE, em particular com o Programa Estratégico Sistema Integrado de Monitoramento de Fronteiras (SISFRON) e o Programa Estratégico de Proteção da Sociedade (PROTEGER), nos quais as duas brigadas citadas acima são protagonistas. Além disso, o Prg EE GUARANI conduz as suas ações de modo a aumentar a interoperalidade do EB com a Marinha do Brasil e a Força Aérea Brasileira.

No avanço do Prg EE GUARANI, o $1^{\circ}$ Batalhão de Infantaria Motorizado, unidade da $9^{\text {a }}$ Brigada de Infantaria Motorizada que possui grande experiência de atuação em Operações de Garantia da Lei e da Ordem na cidade do Rio de Janeiro, também começou a receber as VBTP-MSR GUARANI recentemente. As características já mencionadas dessa viatura conferem a ela a versatilidade necessária para o seu emprego efetivo em eventuais operações em centros urbanos, ampliando consideravelmente a capacidade de pronta-resposta da brigada considerada (Figura 5).

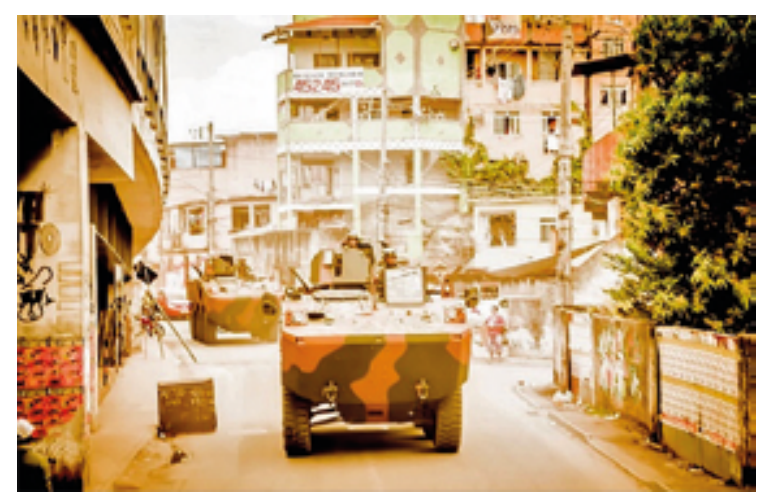

Figura 5. VBTP-MSR 6x6 GUARANI em Operações da Garantia da Lei e da Ordem. (Fonte: CCOMSEX).

Verifica-se que a mecanização da $15^{\mathrm{a}} \mathrm{Bda} \operatorname{Inf} \mathrm{Mec}$, anteriormente uma Brigada de Infantaria Motorizada, está sendo exitosa na sua contribuição para o atingimento do objetivo proposto pelo Prg EE GUARANI de transformar a Infantaria Motorizada, pois deu novas capacidades para essa Arma, possibilitando o cumprimento de novas missões, especialmente as relacionadas às operações de reconhecimento e segurança. Nesse mesmo sentido, a $4^{\mathrm{a}} \mathrm{Bda} \mathrm{C} \mathrm{Mec}$, ao obter os resultados do Prg EE GUARANI, otimizou as suas capacidades que são inerentes à Arma de Cavalaria, e vem cumprindo assim, as suas já consagradas missões de uma forma mais efetiva junto à fronteira brasileira. 


\section{Conclusão}

O Prg EE GUARANI vem demostrando uma grande capacidade de adaptação à evolução conjuntural e doutrinária. O programa foi concebido para entregar produtos e resultados ajustados ao conceito operativo do $\mathrm{EB}$, que visualiza o emprego dos seus meios em qualquer cenário no amplo espectro dos conflitos, desde as ações dissuasivas em tempo de paz até as grandes campanhas militares em tempo de guerra. Como medida quantitativa do nível da Transformação pela qual o EB está passando em função do programa em questão, ressalta-se que o número de VBTP-MSR GUARANI entregues à Força Terrestre já ultrapassou a quantidade de Urutus que o EB possuía antes da existência do Prg EE GUARANI.

Face às suas características, a VBTP-MSR GUARANI vem sendo empregada com sucesso em diferentes missões e ambientes operacionais, tanto no campo como em áreas urbanas. Essa grande versatilidade, aliada aos seus compensadores custos de aquisição e manutenção, fazem dessa viatura uma opção viável também para outras forças armadas, particularmente as sul-americanas. Além disso, o seu sistema de armas permite o emprego do poder de fogo de modo seletivo, reduzindo, assim, a possibilidade de ocorrência de efeitos colaterais indesejados, possibilitando a perfeita adequação do blindado a regras de engajamento com características muito restritivas, proporcionando mais confiança aos comandantes em todos os níveis quando ocorre situações de emprego da força militar em áreas humanizadas. A VBTP-MSR GUARANI pode incorporar ainda meios de comunicação que possibilitam a interoperabilidade das tropas mecanizadas com forças militares de outra natureza, ou que atuem em outros domínios do campo de batalha moderno.

Verifica-se que as oscilações ou reduções orçamentárias são o principal óbice para a perenidade dos programas estratégicos, em especial o Prg EE GUARANI. Entretanto, a elaboração de um plano es- tratégico focado na obtenção das $\mathrm{CO}$ necessárias ao cumprimento das missões constitucionais da Força, incluindo ações estratégicas devidamente priorizadas, contribui decisivamente para evitar ou mitigar a descontinuidade do programa em questão. Nesse sentido, a importância do Ptf EE pode ser sintetizado na frase: "eficácia, eficiência e efetividade, com o emprego racional e otimizado de recursos, só podem ser mensurados e alcançados, quando se trata do gerenciamento de programas e projetos estratégicos, com uma metodologia consistente" (Comandante do Exército, 2017).

Conclui-se assim, que o desenvolvimento de produtos de defesa traz grandes benefícios para a sociedade brasileira, fomentando a pesquisa científica e tecnológica e gerando milhares de empregos e renda, contribuindo, dessa maneira, para girar a economia do País. Segundo pesquisa da Associação Brasileira das Indústrias de Materiais de Defesa e Segurança (ABIM$\mathrm{DE})$, cada $\mathrm{R} \$ 1,00$ investido no setor de Defesa, gera um movimento de $\mathrm{R} \$ 3,66$ na economia brasileira (EPEx, 2019). Sem considerar eventuais aquisições de outras forças armadas, o Prg EE GUARANI, somente no âmbito interno, já está possibilitando uma significativa revitalização da BID.

Por fim, o Prg EE GUARANI consolida um amplo esforço conjunto e orquestrado de muitos anos do EB, da BID e de instituições acadêmicas, contribuindo com o desenvolvimento sustentável, a integração, a paz social e a defesa dos interesses nacionais. As CMT obtidas pelo Prg EE GUARANI dão ao EB o poder dissuasório compatível com a estatura político-estratégica do País, garantindo a presença do Estado em todos os rincões do território nacional e ampliando a sua projeção no cenário internacional. Ademais, o programa consolida o Processo de Transformação do Exército, ampliando a capacidade de atuação da Força e contribuindo para a Defesa da soberania do País.
[1] CCOMSEX. (8 de agosto de 2012). Exército Brasileiro assina contrato para aquisição de 86 viaturas Guarani. Fonte: Exército Brasileiro: http://www.eb.mil.br/exercitobrasileiro

[2] CCOMSEX. (2015). O Projeto de P\&D da Família de Blindados Guarani. Verde-Oliva, 68.

[3] CCOMSEX. (16 de Julho de 2019). A Iveco Veículos de Defesa entrega ao Exército a viatura $N^{\circ} 400$ do Programa Estratégico Guarani. Fonte: Exército Brasileiro: https:// www.eb.mil.br/web/noticias/ noticiario-do-exercito/-/asset publisher/MjaG93KcunQI/content/ id/10184203

\section{REFERENCIAS}

[4] CEEEx. (2019). CEEEx Institucional. (E. Brasileiro, Editor, \& SG 2 - EME) Fonte: Centro de Estudos Estratégicos do Exército: http://www.ceeex.eb.mil.br/index.php/ editoria-a

[5] Chesbrough, H. W. (2006). Open Innovation: A New Paradigm for Understanding Industrial Innovation. Em H. W. Chesbrough, Open Innovation: Researching $a$ New Paradigm (p. 27). Berkeley, Califórnia, Estados Unidos: Oxford University Press.
[6] Comandante do Exército. (2016). EB10-IG-01.018 - Instruções Gerais para a Gestão do Ciclo de Vida dos Sistemas e Materiais de Emprego Militar (1 $1^{\mathrm{a}}$ ed.). Brasília, DF, Brasil: Exército Brasileiro.

[7] Comandante do Exército. (2017) EB10-N-01.004 - Normas para Elaboração, Gerenciamento e Acompanhamento do Portfólio e do Programas Estratégicos do Exército Brasileiro (NEGAPORT-EB) (1 ${ }^{\text {a }}$ ed.). Brasília, DF, Brasil: Exército Brasileiro.

[8] Comandante do Exército. (2019). Diretrizes do Comandante do Exército. Brasília, DF, Brasil: Exército Brasileiro. 
[9] Comandante do Exército. (2019). EB10-D-01.001 - Diretriz para Implantação do Sistema Defesa Indústria e Academia de Inovação (SisDIA de Inovação). Brasília, DF, Brasil: Exército Brasileiro.

[10] Covarrubias, J. G. (novembro dezembro de 2007). Os Três Pilares de uma Transformação Militar. Military Review, 16-24.

[11] DCT. (2020). Missão. (Exército Brasileiro) Fonte: Departamento de Ciência e Tecnologia: http://www.dct. eb.mil.br/index.php/historia

[12] DCT. (2020). SisDIA. (Exército Brasileiro) Fonte: Departamento de Ciência e Tecnologia: http://sisdia.dct. eb.mil.br/sisdia/assuntos/editoria-a/ institucional/sisdia

[13] DCT. (2020). Sistema Defesa, Indústria e Academia de Inovação. (Exército Brasileiro) Acesso em 2020, disponível em Departamento de Ciência e Tecnologia: http://sisdia.dct. eb.mil.br/sisdia/assuntos/editoria-a/ institucional/sisdia

[14] DCT. (s.d.). Projeto Guarani. Fonte: Departamento de Ciência e Tecnologia: http://www.dct.eb.mil. br/index.php/component/content/ article?id=88:projeto-guarani

[15] EME. (1996). IP 100-1 - Bases para a Modernização da Doutrina de Emprego da Força Terrestre (Doutrina Delta) (1 $1^{\mathrm{a}}$ ed.). Brasília, DF, Brasil: Exército Brasileiro.

[16] EME. (10 de junho de 2010). Diretriz para Implantação do Processo de Transformação do Exército Brasileiro. Portaria $N^{o}$ 075-EME. Brasília, DF, Brasil: Exército Brasileiro.
[17] EME. (2010). O Processo de Transformação do Exército ( 3 ed.). Brasília, DF, Brasil: Exército Brasileiro.

[18] EME. (2013). Bases para a Transformação da Doutrina Militar Terrestre. Brasília, DF, Brasil: Exército Brasileiro.

[19] EME. (2013). Concepção de Transformação do Exército 20132022. Brasília, DF, Brasil: Exército Brasileiro.

[20] EME. (2015). EB20-C-07.001 Catálogo de Capacidades do Exército (2015-2035). Brasília, DF, Brasil: Exército Brasileiro.

[21] EME. (2018). EB20-D-08. 025 Diretriz de Implantação do Programa Estratégico do Exército GUARANI - Prg EE GUARANI. Brasília, DF, Brasil: Exército Brasileiro.

[22] EME. (2019). EB 10-P-01.007 Plano Estratégico do Exército 20202023. Brasília, DF, Brasil: Exército Brasileiro.

[23] EME. (2019). Política Militar Terrestre 2019. Brasília, DF, Brasil: Exército Brasileiro.

[24] EME. (2020). EPEx. Fonte: EstadoMaior do Exército: http://www.eme. eb.mil.br/index.php/epex

[25] EME. (2020). Institucional. Fonte: Estado-Maior do Exército: http:// www.eme.eb.mil.br/index.php/ institucional

[26] EPEx. (2018). Revista - Portfólio Estratégico do Exército. Brasília, DF, Brasil: Exército Brasileiro.

[27] EPEx. (2019). Publicações. Fonte: Escritório de Projetos do Exército: http://www.epex.eb.mil.br/index.php/ publicacoes
[28] MEPDG. (2018). Estratégia Nacional de Desenvolvimento Econômico e Social. Brasília, DF, Brasil: Brasil. Fonte: http://www.planejamento.gov. br/assuntos/planeja/endes

[29] MEPDG. (2020). Plano Plurianual (PPA). Fonte: Ministério da Economia: http://www.economia. gov.br/assuntos/planejamento-eorcamento/plano-plurianual-ppa

[30] MICS - ABDI. (2020). Agenda brasileira para a Indútria 4.0. Fonte: Indústria 4.0: http://www.industria40. gov.br/

[31] Ministério da Defesa. (2012). Estratégia Nacional de Defesa. Brasília, DF, Brasil: Brasil. Fonte: https://www.defesa.gov.br/component/ content/article/145-forcas-armadas/ estado-maior-conjunto-das-forcasarmadas/doutrina-militar/13188publicacoes

[32] Ministério da Defesa. (2012). Política Nacional de Defesa. Brasília, DF, Brasil: Brasil. Fonte: https://www defesa.gov.br/component/content/ article/145-forcas-armadas/estadomaior-conjunto-das-forcas-armadas doutrina-militar/13188-publicacoes

[33] Ministério da Defesa. (2015). MD35-G-01 - Glossário das Forças Armadas ( $5^{\mathrm{a}}$ ed.). Brasília, DF, Brasil: Brasil.

[34] SIPRI. (2019, abril 29). World military expenditure grows to $\$ 1.8$ trillion in 2018. Retrieved janeiro 2020, from Stockholm Internationa Peace Research Institute - SIPRI: https://www.sipri.org/media/ press-release/2019/world-militaryexpenditure-grows-18-trillion-2018 